\title{
U.S. NURSING STUDENTS IN NICARAGUA: A COMMUNITY HEALTH CLINICAL EXPERIENCE
}

Rita L. Ailinger ${ }^{1}$

Ailinger RL. U.S. nursing students in Nicaragua: a community health clinical experience. Rev Latino-am Enfermagem 2002 janeiro-fevereiro; 10(1):104-5.

During the January intercession each year students at George Mason University (GMU) in Virginia, USA, have the opportunity to take two week intensive courses for credit. While their fellow students are vacationing or working, students gain credit in a shorter time. For the last seven years, the College of Nursing and Health Science at GMU has offered an intensive community health clinical experience for 6-8 students in Nicaragua. The experience is led by the authors. This article describes some of the experiences of students in the most recent cohort. As we departed for the six hour flight from Virginia to Managua, students were excited and anxious about the journey they were about to undertake. They asked themselves if they were ready for the two week intensive clinical learning and cultural immersion in a Spanish-speaking developing country.

Upon arrival in Managua, we were met at the airport by Carmen Benavides, MSP, our Nicaraguan faculty member counterpart. She is the director of the school of nursing at the Universidad Politecnica de Nicaragua (UPOLI) and can be described as a dynamic public health nurse and born teacher. During the experience, the GMU students and faculty in a small clean hotel about one mile from UPOLI.

In the first afternoon we had an orientation with Lidya Zamora, an MSN graduate from GMU, who was the director of the school of nursing for 15 years and is now the Provost of the university. Lidya is enrolled in the GMU doctoral program in nursing and will be the first nurse in her country to receive a doctorate just as she was the first nurse to receive an MSN in 1992.

The first full day's orientation included information sessions on demographics and epidemiology of Nicaragua and the community (barrio) where we would be working. Nicaragua is the second poorest country in Latin America and has an unemployment rate of over $60 \%$ and an average annual income of $\$ 495$. In the afternoon we headed to the barrio to meet the health promoters (brigadistas), community leaders and the families to which the students were assigned. The barrio is a former squatter settlement that is only 10 years old. There are almost 2000 people living in the barrio, in shacks made of scrap wood, cinder blocks and tin roofs. The dirt streets are rutted with cavernous ditches where people burn their trash. Most homes have latrines.

Each undergraduate student was assigned a family to work with over the course of two weeks. Their assignment was to assess the family as a whole and then each family member. They then were to prioritize their nursing interventions. Students also conducted a community assessment of the barrio in which they interviewed randomly selected households about their basic health needs and developed a community health plan. At the health center the GMU students worked in clinics: prenatal, newborn, pediatrics, oral rehydration, epidemiology $\mathrm{TB}$, and family planning.

In addition to the undergraduate students, we also included two graduate nursing students from the nurse practitioner (NP) program. They were called upon to be consultants to the undergraduate students regarding their families, helping them with assessments, diagnoses and treatment. They also interacted with the local nurses in formal and informal meetings to share ideas about nursing in the hospital and the community.

Last, but not least, they were able to function as advanced practice nurses in the real world, care for truly underserved people, and to think on their feet, in Spanish, with few supplies and resources. This experience serves as a strong foundation for them when they begin practice as certified nurse practitioners.

Each day after working for several hours in the clinics, seeing the nurses function with minimal resources, we headed to the barrio where students visited their families. In order to do their physical assessments on family members the students accompanied the families to the nursing center in the barrio, and there they examined family members under the guidance of the NP students.

The nursing center in the barrio was the dream of Lidya Zamora who sought private donations from friends in the US and Canada and with the administrative support of UPOLI built the Academic Nursing Center. It opened in December, 2000, and has 3

\footnotetext{
${ }^{1} \mathrm{PhD}, \mathrm{RN}$, Professor - College of Nursing and Health Science - George Mason University, e-mail: railinge@gmu.edu
} 
examining rooms, a classroom, and a small lending library for children.

The center will meet many of the health needs of the people in the barrio by providing primary health care, prevention and education. The center is staffed by UPOLI faculty and students. When our nursing students found treatable conditions such as parasites, visual problems, infections, high blood pressure, the NP students wrote prescriptions for them to be seen at a local clinic. One of the highlights of the students community experience is the health fair which was held in the nursing center. Approximately 170 people including about 100 children flocked to the nursing center on an afternoon from 2-4 PM to hear health education talks (charlas) by nursing students. Topics for adults included: nutrition, cognitive development for babies and malaria and for children songs and demonstrations on handwashing and teeth brushing. Games such as pin the tail on the donkey and sack races were held and folkloric dancing was showcased by the local children. Adults had blood pressures taken and health advice was offered.
The nursing center was festooned with balloons and streamers and cookies and juice were served. It was a joyous albeit overcrowded scene.

The two weeks of clinical work ended in the GMU students' tearful goodbyes to barrio families and brigadistas. Students expressed tremendous satisfaction in what they had accomplished and learned in their experience. As one student wrote, "it made me realize why I chose nursing and the experience has motivated me to work in international health".

This program has become of model for two additional community health clinical experiences during the intercession. One is in Barbados and the other on Smith Island, a rural island populated by 300 people in the Chesapeake Bay, Virginia. These cross-cultural experiences enrich the personal and professional lives of the students and faculty involved and have long term effects in career decisions for our nursing graduates. 